University of South Florida

DIGITAL COMMONS

Digital Commons @ University of

@ UNIVERSITY OF SOUTH FLORIDA

South Florida

$11-2008$

\title{
Analysis of Large-scale Ocean Bottom Pressure Variability in the North Pacific
}

Don P. Chambers

University of Texas, dchambers@marine.usf.edu

Josh K. Willis

California Institute of Technology

Follow this and additional works at: https://digitalcommons.usf.edu/msc_facpub

Part of the Marine Biology Commons

\section{Scholar Commons Citation}

Chambers, Don P. and Willis, Josh K., "Analysis of Large-scale Ocean Bottom Pressure Variability in the North Pacific" (2008). Marine Science Faculty Publications. 178.

https://digitalcommons.usf.edu/msc_facpub/178

This Article is brought to you for free and open access by the College of Marine Science at Digital Commons @ University of South Florida. It has been accepted for inclusion in Marine Science Faculty Publications by an authorized administrator of Digital Commons @ University of South Florida. For more information, please contact digitalcommons@usf.edu. 


\title{
Analysis of large-scale ocean bottom pressure variability in the North Pacific
}

\author{
Don P. Chambers ${ }^{1}$ and Josh K. Willis ${ }^{2}$ \\ Received 23 May 2008; revised 11 August 2008; accepted 28 August 2008; published 4 November 2008.
}

[1] We use the leading empirical orthogonal functions (EOFs) of ocean bottom pressure (OBP) derived from an ocean model and the technique of EOF reconstruction to reduce noise in the large-scale OBP variations derived from the Gravity Recovery and Climate Experiment (GRACE). The subsequent OBP variations from the model and GRACE are then examined in the North Pacific between January 2003 and May 2007. Although annual and semiannual variations are similar, GRACE observes large interannual fluctuations poleward of $30^{\circ}$, where OBP increases from a low of nearly $3 \mathrm{~cm}$ below normal in early 2003 to normal throughout 2004 and 2005, then an increase of nearly the same magnitude in 2006. These fluctuations have also been observed in OBP inferred from satellite altimetry corrected for steric variations computed from Argo float data. Since GRACE and steric-corrected altimetry are completely independent observations of OBP, we conclude that the model has errors or deficiencies in predicting the interannual OBP fluctuations in the North Pacific.

Citation: Chambers, D. P., and J. K. Willis (2008), Analysis of large-scale ocean bottom pressure variability in the North Pacific, J. Geophys. Res., 113, C11003, doi:10.1029/2008JC004930.

\section{Introduction}

[2] Investigations of nontidal ocean bottom pressure (OBP) and barotropic sea level have been meager in the literature until recently, even though Gill and Niiler [1973] suggested that barotropic fluctuations poleward of $30^{\circ}$ latitude might be a significant portion of seasonal sea level variability. OBP is a difficult quantity to measure directly, and most measurements have been restricted to shallow shelf areas and not the deep ocean. Deep ocean measurements have typically been made in only a few limited regions and for relatively short periods, such as experiments to measure OBP variability in the Antarctic Circumpolar Current [e.g., Hughes and Smithson, 1996], and its transport [e.g., Woodworth et al., 1996].

[3] The first global study of large-scale OBP in the deep ocean was done by Ponte [1999], who used output from a numerical model to show that there were large seasonal fluctuations in OBP in the north Pacific and Southern Ocean. The OBP variations were correlated over regions as wide as $3000 \mathrm{~km}$ and had amplitudes exceeding $3 \mathrm{~cm}$ of equivalent sea level. At the time that Ponte's study was published, NASA was considering the launch of the Gravity Recovery and Climate Experiment (GRACE), a mission with the goal of measuring the time-variable gravity field of the earth. Wahr et al. [1998] had demonstrated that if the gravity field estimates were sufficiently accurate, then the

\footnotetext{
${ }^{1}$ Center for Space Research, University of Texas at Austin, Austin, Texas, USA.

${ }^{2}$ NASA Jet Propulsion Laboratory, California Institute of Technology, Pasadena, California, USA.
}

Copyright 2008 by the American Geophysical Union. 0148-0227/08/2008JC004930 data could be used to infer a number of important geophysical processes, such as changes in land water storage, melting of ice sheets, and changes in ocean bottom pressure.

[4] The GRACE mission was launched in March 2002 and began operating nearly continuously in August of that year [Tapley et al., 2004]. The early releases of the data had errors of the same order as the expected OBP signals [Wahr et al., 2004], so studies of the OBP variability were limited. Chambers et al. [2004] demonstrated that GRACE could measure the variation in the global mean ocean mass (and hence OBP) quite accurately. Kanzow et al. [2005] were the first to specifically examine more local OBP variations from the early GRACE data, but found that the RMS variations were much higher than expected, especially in regions where there should be little or no barotropic signals. However, Bingham and Hughes [2006] found that by using an Empirical Orthogonal Function (EOF) analysis, the seasonal mode of OBP variation in the North Pacific could be extracted from GRACE data, and that it agreed qualitatively with that found in an ocean model. Zlotnicki et al. [2007] differenced GRACE OBP variability on either side of the Antarctic Circumpolar Current and found seasonal transports in agreement with two ocean models. Chambers [2006a] also used an EOF analysis to extract global seasonal steric sea level variations from altimetry corrected for OBP from GRACE that agreed well with climatological steric variations.

[5] As the GRACE science data centers continued to refine their processing of the satellite data and improve the quality of the gravity field solutions, investigators also found ways to reduce some of the systematic errors that remained in the data that especially limited their usefulness over the ocean. Swenson and Wahr [2006] discovered a 
correlated error in the gravity coefficients that propagated into north-south "stripes" in the mapped data. They proposed an ad hoc filter to reduce these "stripes," which Chambers [2006b] adapted to improve maps of OBP variability from GRACE and found an error reduction anywhere from 20 to $50 \%$, depending on the amount of smoothing applied. Ponte et al. [2007] used these improved grids to study the global seasonal OBP variability, and found better agreement with models than had been observed previously. Song and Zlotnicki [2008] recently used the same data to examine OBP in the North Pacific and found a large interannual variation in early 2003 that they speculate is related to changes in the wind stress forcing of the subpolar gyre related to El Niño-Southern Oscillation (ENSO).

[6] Since the publication of these most recent articles, the GRACE science data centers have produced a new release of GRACE gravity field coefficients [Bettadpur, 2007]. The goal of this investigation is to use these newly processed data along with a filtering technique known as EOF Reconstruction [e.g., Smith et al., 1996] to compute improved maps of OBP variability from GRACE in the North Pacific. The data will be compared with the OBP from an ocean model in terms of the seasonal modes, interannual variability, and trends from January 2003 until early 2007. We chose the North Pacific for this initial study because it has been the most studied basin in terms of OBP, and because we can infer another independent measure of OBP in this region from satellite altimetry corrected for steric profiles from Argo floats. Previous studies of the North Pacific OBP from GRACE [Kanzow et al., 2005; Bingham and Hughes, 2006; Ponte et al., 2007; Song and Zlotnicki, 2008] have made qualitative comparisons with ocean models. After the EOF Reconstruction filtering, we will be able to make more quantitative comparisons with the ocean model and other data sets.

[7] The next section will review the data we have used and some special processing. In section 3, we will describe the EOF Reconstruction (EOFR) filtering of the GRACE data, and then compare the results with the ocean model and steric-corrected altimetry.

\section{Data Processing}

[8] Before discussing specific data and models used in this study, ocean bottom pressure must be strictly defined. We will express OBP variation in terms of the equivalent sea level change $(\Delta \eta)$, which is related to $\Delta$ OBP by

$$
\Delta \mathrm{OBP}=\rho g \Delta \eta
$$

where $\rho$ is an average density of seawater and $g$ is the mean acceleration of gravity [e.g., Ponte, 1999].

[9] Assuming tides have been removed from the data, there are three sources of OBP variability on monthly and longer time-scales. Locally, the largest is from internal mass redistribution in the ocean, forced by winds and changes in the circulation. These OBP changes have amplitudes of several $\mathrm{cm}$ over several thousand $\mathrm{km}$. There are also two smaller components of OBP variability that are approximately uniform over the ocean bottom (the component due to water mass entering and leaving the ocean as part of the global water cycle [e.g., Chen et al., 1998; Chambers et al., 2004] and the mean atmospheric pressure over the ocean [e.g., Ponte, 1999]). These two components are dominantly seasonal, with amplitudes of approximately $8 \mathrm{~mm}$ (ocean mass) and $6 \mathrm{~mm}$ (atmosphere). In this article, we will examine the total OBP variation as it would be measured by an OBP gauge; i.e., the sum of all these components.

[10] We use maps of OBP that have been derived from the most recent GRACE gravity field solutions (Release-04) from the Center for Space Research (CSR) at the University of Texas, Austin that are publicly available from the GRACE Tellus Web site (http://gracetellus.jpl.nasa.gov/ month_mass.html). The details of the processing are discussed in a document on the Website [Chambers, 2007]. For this article, the most important aspects of the data are that they have been filtered to reduce the effects of a correlated error that causes north-south "stripes" in the maps [Swenson and Wahr, 2006; Chambers, 2006b], they have been corrected for effects of glacial isostatic adjustment using a recent model, and they represent the full nontidal monthly ocean bottom pressure variation, including the effects of the mean atmosphere, mean ocean mass, and internal mass redistribution. We use the maps that have been smoothed in space with a 300-km Gaussian. Monthly grids are available from August 2002 until December 2007, except for June 2003 and January 2004, when no solutions exist.

[11] We also use monthly average maps of OBP from a version of the MIT general circulation model [Marshall et $a l ., 1997]$ that is run at Jet Propulsion Laboratory (JPL) as part of the Estimating the Circulation and Climate of the Ocean (ECCO) consortium, which we will denote as JPL ECCO. We specifically use the version that has assimilated altimetry and in situ profile data (run dr066b7) and is forced by winds, pressure, and heat and freshwater fluxes from the National Center for Environmental Prediction (NCEP) operational analyses products [Fukumori et al., 1999]. We have monthly OBP from January 2003 until May 2007. The JPL_ECCO model extends only between $\pm 78^{\circ}$ latitude, so does not model OBP fluctuations in the Arctic Ocean or near Antarctica. The JPL_ECCO model uses the Boussinesq approximation, which causes spurious mean OBP signals [Ponte, 1999]. These can be removed by estimating and removing the average of over the spatial domain each month [Ponte, 1999]. However, this means that the model will only represent the mass redistribution portion of the OBP signal. In order to quantify the total OBP variation, we have to add back the components from the mean ocean mass and mean atmosphere [Ponte et al., 2007]. In this analysis, we use a time series of mean ocean mass estimated from GRACE data [e.g., Willis et al., 2008] and atmospheric pressure from the ECMWF model that is used in the GRACE processing [Flechtner, 2007]. Thus globally averaged OBP from the adjusted JPL_ECCO model will be identical to that of GRACE by design. No additional smoothing has been done on the JPL_ECCO data.

[12] There is one other significant change to the data we have made. While investigating interannual fluctuations in ocean mass from the GRACE observations [Willis et al., 2008], we discovered a possible problem in the data related to the K2 tide, which aliases to a period of approximately 1400 days $(\sim 3.8$ years) for the GRACE orbit. We found a 

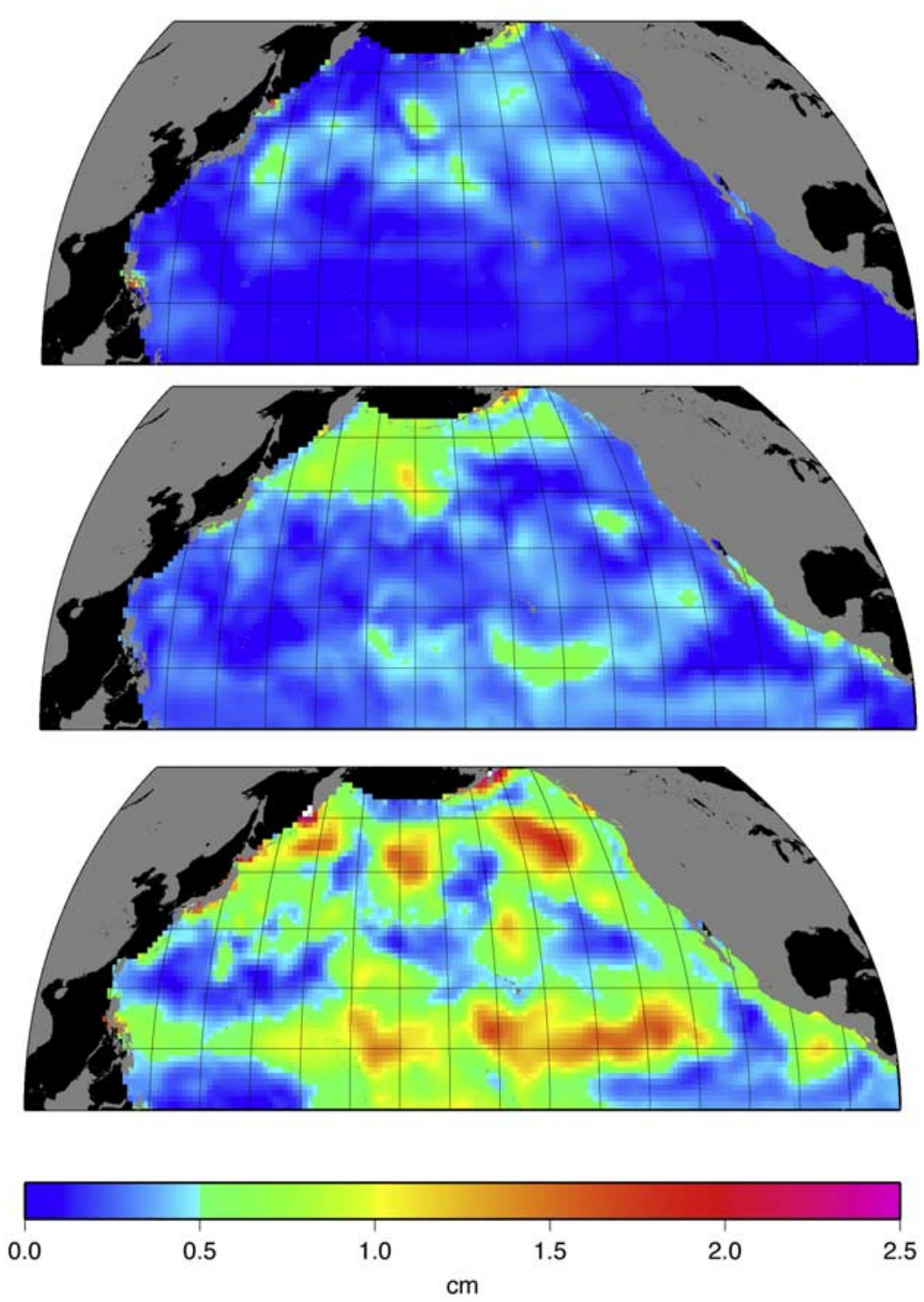

Figure 1. Amplitudes at the K2 tide alias for GRACE (1400 days) for JPL_ECCO (top), GRACE from CSR processing (middle), and GRACE from GFZ processing (bottom).

distinct 1400-day difference in the global ocean mass computed from coefficients processed by CSR and the other data processing center, GeoForschungsZentrum (GFZ). We linked the difference to the fact that CSR and GFZ use slightly different models for the K2 ocean tide. If we examine the amplitudes of OBP in the North Pacific at a 1400-day period predicted by JPL_ECCO and GRACE data from both CSR and GFZ (Figure 1), we note that there is significantly higher variability in the GRACE data than is predicted by the model. Although there are a few locations where JPL_ECCO predicts amplitudes of nearly $0.5 \mathrm{~cm}$ at the perio $\bar{d}$, the CSR GRACE data have amplitudes approaching $1 \mathrm{~cm}$ while the GFZ GRACE data have amplitudes of more than $2 \mathrm{~cm}$ in the same locations. This suggests there is a K2 tide error in the GRACE data, with more error in the GFZ solutions than the CSR solutions. To reduce this $\mathrm{K} 2$ error, we have utilized the CSR data (because it has lower amplitudes at the period and presumably is less affected by the error to begin with) and have estimated and removed the 1400-day oscillation from the data. The amplitude was estimated simultaneously with a bias, trend, annual and semiannual periods, as well as a 161-day period (which is the alias of the S2 tide in GRACE). Although these other periods are estimated to help separate the 1400-day period, only the 1400-day period is removed. Since this will also remove a small amount of real signal at this period, we also estimated and removed a 1400-day sinusoid from the JPL_ECCO grids before comparisons using the same procedure.

[13] Satellite altimetry also measures the sea level signature related to OBP variations, as well as variations related to changes in the ocean density. OBP can be estimated from altimetry if the density fluctuation component is removed [e.g., Vivier et al., 2005]. Here we use in situ temperature and salinity profiles from the Argo array of profiling floats to estimate changes in ocean density. Delayed-mode data were used where available, and Argo quality control flags were used to eliminate spurious measurements. Data from 
marginal and inland seas were excluded. Additional quality control was performed in two steps. First, all profile data were grouped together in $10^{\circ}$ latitude bands and visually inspected to remove gross outliers. For each profile, steric height at the surface was then computed relative to $900 \mathrm{~m}$. Steric height at the location of each profile was also computed from the WOCE gridded hydrographic climatology (WGHC) [Gouretski and Koltermann, 2004]. WGHC steric height was then subtracted from the observed steric height and data were divided into $5^{\circ} \times 5^{\circ}$ horizontal boxes. A standard deviation check was performed in each box, and steric heights more than three standard deviations away from the $5^{\circ} \times 5^{\circ}$ mean were removed. Less than $1 \%$ of Argo data were eliminated using this procedure. After quality control, about 80,000 profiles remained between July 2003 and the June 2007 in the North Pacific. The 900-m depth was chosen to provide maximal spatial and temporal coverage, as many floats do not profile deeper than $1000 \mathrm{~m}$, particularly at low latitudes.

[14] The sampling of Argo profiles and altimeter data are very different in space and time. In a 10-day period, there is about one profile in a $3^{\circ}$ area, while there may be hundreds of altimeter measurements from multiple altimeters over the same area and time window. To compute OBP at the Argo float locations, we use altimetry sea level anomalies (SLAs) from high-resolution gridded maps based on multiple altimeters [Ducet et al., 2000] provided by AVISO. We recenter the grids to the same time period as the Argo floats, and then interpolate the altimeter gridded data to the time and location of the Argo profile, before differencing to estimate a local OBP anomaly. These local OBP anomalies can then be mapped or averaged and compared to the GRACE and JPL_ECCO results. Estimates of OBP produced in this way will include some error due to steric variability that occurs below $900 \mathrm{~m}$, as well as nontidal sea level variability that occur on scales shorter than about $150 \mathrm{~km}$ and 7 days, which are not resolved by the altimeter data. Nevertheless, previous works [Antonov et al., 2005; Guinehut et al., 2006], as well as the results below, suggest that such errors are small.

\section{EOF Reconstruction}

[15] Several techniques have been used for some time to spatially interpolate sparse historical data based on EOFs from modern satellite maps. This has been done with sea surface temperature [Shen et al., 1994; Smith et al., 1996; Kaplan et al., 1997, 2000], wind stress [Shriver and O'Brien, 1995], and sea level [Cane et al., 1996; Chambers et al., 2000, 2002; Church et al., 2004], and is often referred to as EOF reconstruction (EOFR). The basic principle of the EOFR technique is that the spatial maps from a principal component analysis are used as multiple covariance basis functions in place of a single covariance function as in optimal interpolation. In essence, the raw data are fit to EOF spatial patterns in a least squares procedure to estimate the temporal coefficients for each mode. A set of scaling parameters equal to the number of EOF modes used is estimated for each time step. Then, a reconstructed grid is computed by multiplying the estimated scaling parameter for a particular month and the appropriate EOF spatial grid, then summing over all the EOF modes. The reconstructed grid will have the same spatial density as the EOF spatial map.

[16] Although the GRACE OBP grids are not sparse, the same techniques used in EOF reconstruction can be used to extract the OBP signals in the GRACE data that are spatially correlated with the OBP in JPL ECCO grids and potentially reduce the noise in the maps. At first glance, the RMS variability of the GRACE OBP is so large that no correlation with the model OBP variability is evident (Figure 2). However, if a "noise floor" of $1.5 \mathrm{~cm}$ RMS is subtracted, then some regions of the GRACE OBP variability seem reasonable, such as in the North Pacific [see also, Ponte et al., 2007]. Applying an EOF reconstruction to the GRACE data should help remove the effects of any temporally and spatially uncorrelated signals in the GRACE OBP maps. The exact process we use is described in the following paragraphs.

[17] The EOFs used in this research are obtained from a principal component analysis of the monthly JPL_ECCO maps for only the North Pacific (Figure 2). We have removed data from the shallow seas, because certain areas (notably the South China Sea) tend to have very large month-to-month OBP variations in the model and distort the ranking of the EOF modes in the open ocean, where we are most interested. The JPL ECCO OBP grids are formulated into an $m \times n$ matrix, $H$, where $m$ is the number of spatial grid points and $n$ is the number of monthly grids. The matrix, $H$, is then separated into three matrices through a singular value decomposition of the data [Priesendorfer, 1988]:

$$
H=X \Lambda P
$$

where $X$ is an $m \times n$ matrix whose columns form the EOFs of the decomposition, $\Lambda$ is an $n \times n$ matrix whose diagonal values are the eigenvalues of $H$, and $P$ is an $n \times n$ matrix whose rows represent the principal components associated with each EOF mode. The column vectors (EOFs) of $X$ are orthogonal and form spatial maps of OBP variability. The rows of $P$ are also orthogonal and provide the principal components describing the temporal variability associated with the EOFs. Each EOF is paired with a principal component to form $n$ modes based on the number of monthly grids of OBP. The EOFs and principal components are ordered by the amount of variance of the total signal explained. Thus the first mode will explain the largest percentage of variability and the last modes will explain the least.

[18] The original data can then be represented as a linear combination of the EOF modes and principal components as

$$
\operatorname{OBP}(x, t)=\sum_{k=1}^{N} \alpha_{k}(x) \beta_{k}(t)
$$

where $x$ is the two-dimensional space domain, $t$ is time, $k$ is the EOF mode, $N$ is the maximum number of modes used, $\alpha_{k}(x)$ is the $k$ th column of $X$ from equation (2) normalized by the maximum value, and $\beta_{k}(t)$ is the $k$ th row of $P$ from equation (2) scaled by the associated eigenvalue and the value used to normalize $\alpha_{k}(x)$. Thus the OBP variations 

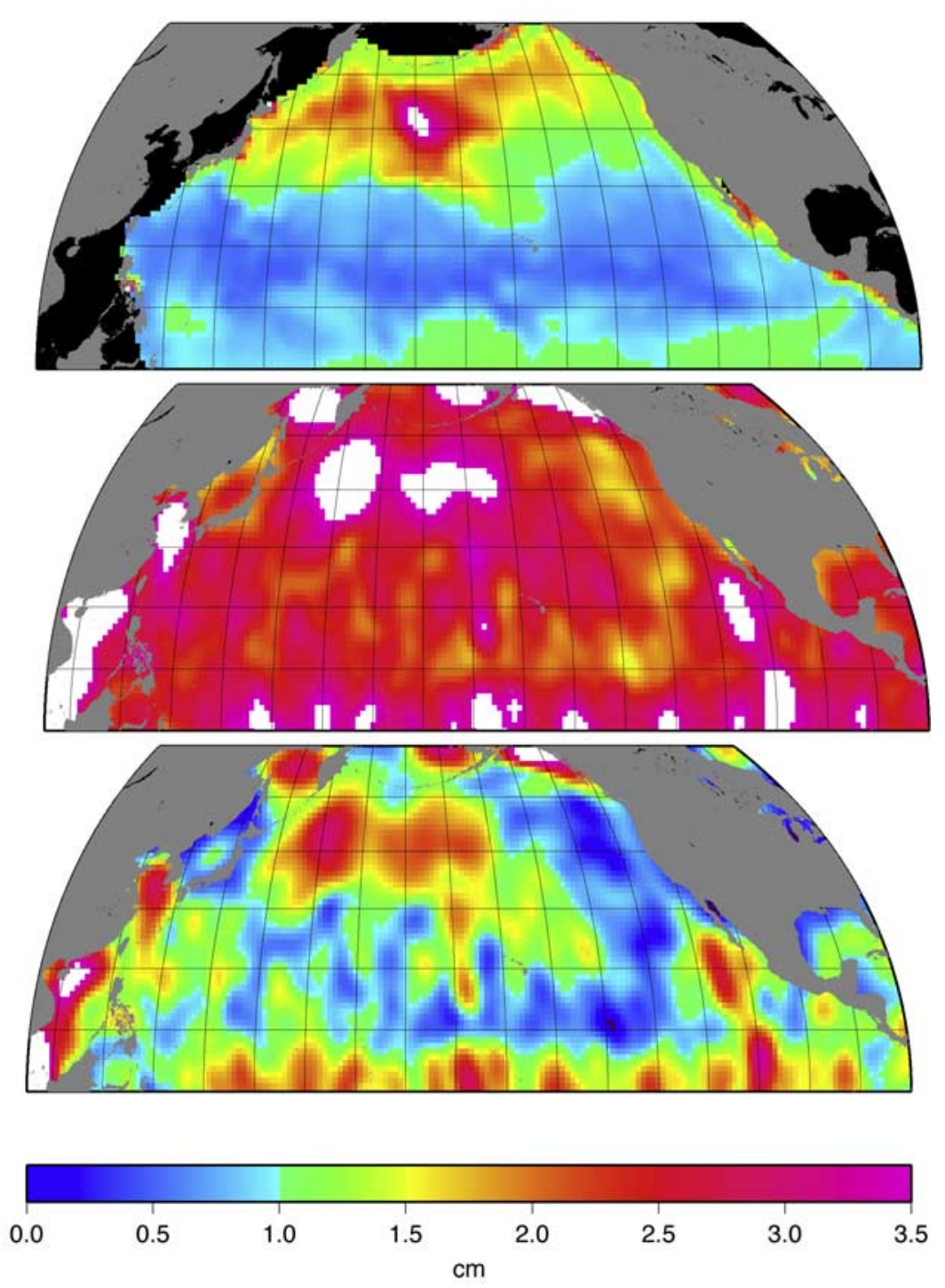

Figure 2. RMS of ocean bottom pressure variability in equivalent sea level for JPL_ECCO (top), GRACE (middle), and GRACE with a 1.5-cm mean RMS removed (bottom).

observed by JPL_ECCO can be decomposed into maps of spatially correlated signals $\left(\alpha_{k}(x)\right)$ along with the associated time variations $\left(\beta_{k}(t)\right)$. The first four modes represent $85 \%$ of the total variance in the North Pacific in the model (Table 1), and more than $90 \%$ of the variance with periods greater of 182 days or greater.

[19] We will use the EOF reconstruction technique described by Smith et al. [1996], which we have used previously to grid sparse tide gauge data using altimeter EOFS [Chambers et al., 2002]. For our current investigation, GRACE OBP grids are used as observations $(O(x, t))$ and the EOF modes from JPL_ECCO are used as the spatial basis functions, $\alpha_{k}(x)$. Associated time variations $\left(W_{k}(t)\right)$ are estimated for each month, $t$, and mode, $k$, to minimize

$$
\varepsilon=O(x, t)-\left[\sum_{k=1}^{N} W_{k}(t) \alpha_{k}(x)\right],
$$

Table 1. Percentage of Cumulative Variance Explained by EOFs Over North Pacific Basin ${ }^{\mathrm{a}}$

\begin{tabular}{lccc}
\hline $\begin{array}{c}\text { EOF } \\
\text { Modes }\end{array}$ & $\begin{array}{c}\text { JPL_ECCO } \\
(\%)\end{array}$ & $\begin{array}{c}\text { GRACE EOFR, } \\
\text { full basin }(\%)\end{array}$ & $\begin{array}{c}\text { GRACE EOFR, } \\
\text { north of } 30^{\circ} \mathrm{N}(\%)\end{array}$ \\
\hline 1 & 57.1 & 23.7 & 43.8 \\
$1-2$ & 73.7 & 26.7 & 44.9 \\
$1-3$ & 81.1 & 30.0 & 46.7 \\
$1-4$ & 85.5 & 31.0 & 47.5 \\
$1-5$ & 88.0 & 33.5 & 51.5 \\
$1-6$ & 90.0 & 33.5 & 53.7 \\
$1-7$ & 91.3 & 34.8 & 55.7 \\
$1-8$ & 92.4 & 35.8 & 56.5 \\
$1-9$ & 93.3 & 36.6 & 56.6 \\
$1-10$ & 94.1 & 38.1 & 57.5 \\
\hline
\end{tabular}

${ }^{\mathrm{a} J P L}$ ECCO is calculated relative to the variance of all the monthly, unsmoothed data $\left(2.1 \mathrm{~cm}^{2}\right)$. GRACE EOFR is calculated relative to the variance of the monthly, $300-\mathrm{km}$ smoothed grids $\left(9.7 \mathrm{~cm}^{2}\right)$. 

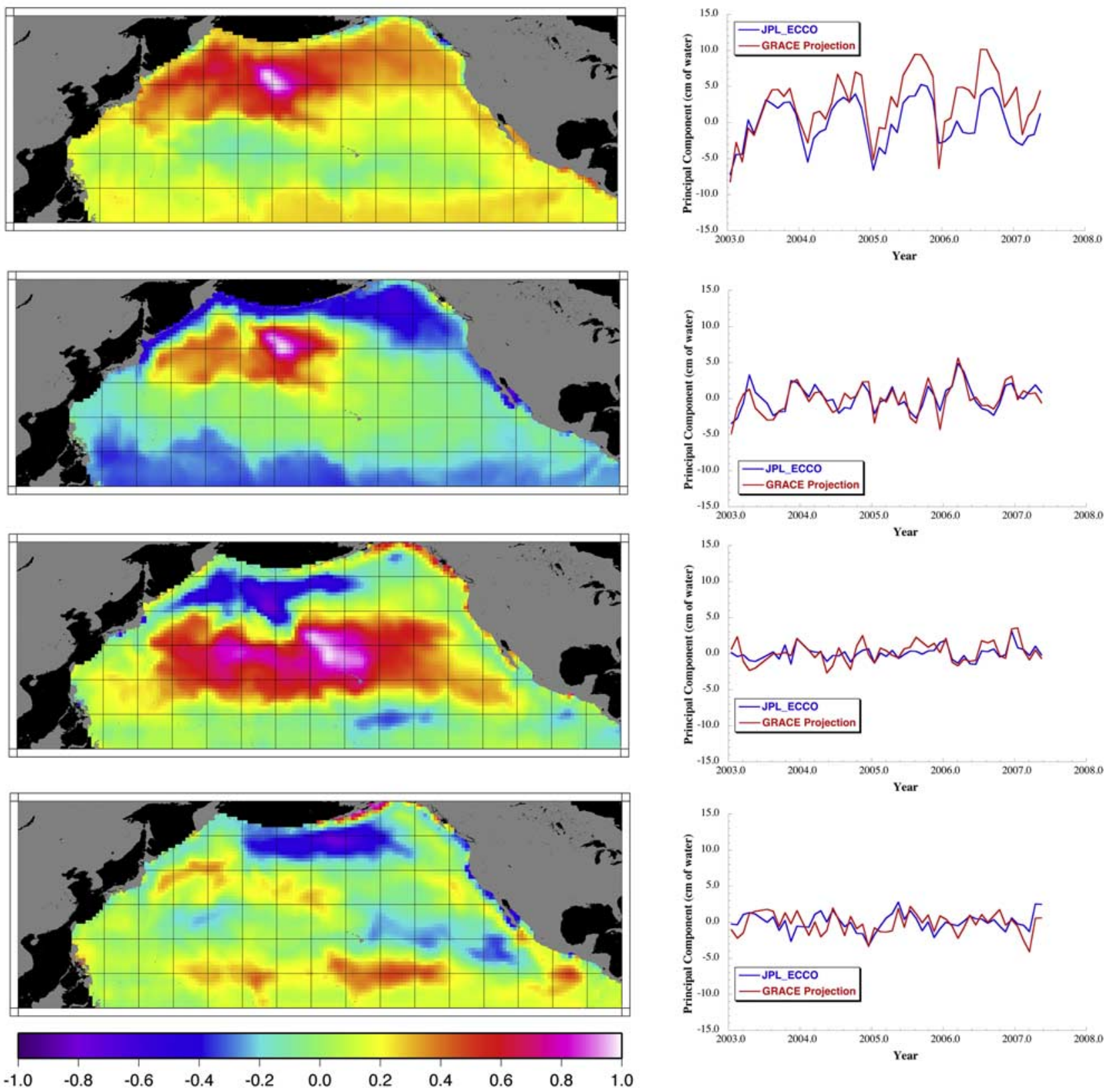

Figure 3. Normalized EOF spatial modes from JPL_ECCO (left column), descending from Mode 1 (top) to Mode 4 (bottom), along with the associated principal component and estimates from GRACE (right column).

using linear least squares estimation. For each month, $N$ parameters will be estimated. Reconstructed grids of OBP $R(x, t)$ are then computed based on the estimated parameters (designated by \langle\rangle )

$$
R(x, t)=\sum_{k=1}^{N}\left\langle W_{k}(t)\right\rangle \alpha_{k}(x) .
$$

[20] There is no inherent restriction to estimating the parameters $W_{k}(t)$ to the exact period that the EOFs patterns were computed, although doing so assumes that the EOF patterns do not change in time [Smith et al., 1996]. This may not be accurate for reconstructing grids at times far away from the time period that the EOFs were made because of very low-frequency oscillations. However, we have found that reconstructions of sea level within several years of the EOF time period are not significantly affected by this [e.g., Chambers et al., 2002]. Thus although we use only JPL_ECCO data from January 2003 until May 2007 to construct the EOFs, we can compute EOFR maps from GRACE data for periods before and after this.

[21] Although the first four modes of the JPL_ECCO EOFs explain most of the variance in the model, we use the first 15 modes in the estimation, in order to sufficiently model the OBP variability. Because the variance of the 

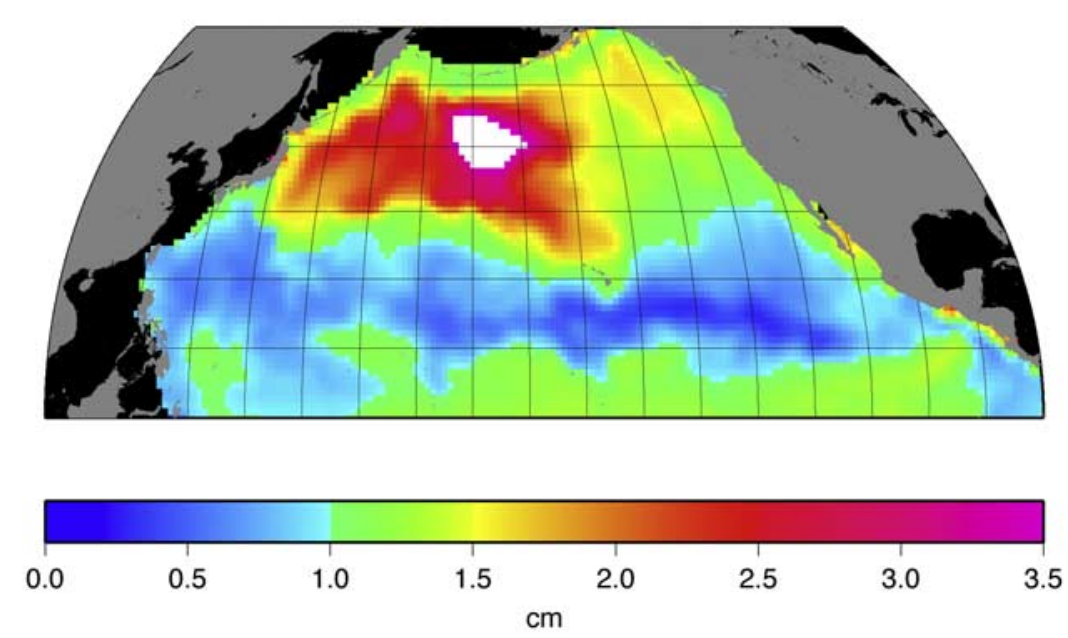

Figure 4. RMS of ocean bottom pressure variability in equivalent sea level for GRACE data after EOFR filtering.

$300 \mathrm{~km}$ GRACE maps is significantly higher than the variance of the JPL_ECCO data $\left(9.7 \mathrm{~cm}^{2}\right.$ compared to $2.1 \mathrm{~cm}^{2}$ ), the variance explained by the EOFR maps relative to the original GRACE data is quite a bit smaller than that explained in the JPL_ECCO data (Table 1), but it is still more than $30 \%$ by the time the first four JPL ECCO EOF modes are used. If the calculation is done only north of $30^{\circ} \mathrm{N}$, the variance explained by an EOFR with the first four modes is nearly $50 \%$. Adding more modes does not significantly improve the variance explained, which would be expected if the majority of the residual signal is noise.

[22] The first four scaling modes and EOFs used to filter the GRACE grids are shown in Figure 3. The leading mode represents a fluctuation in the subpolar gyre at both seasonal and interannual periods that has been observed previously [e.g., Song and Zlotnicki, 2008]. The associated principal component estimate from GRACE has a similar seasonal fluctuation as JPL_ECCO, but a significantly higher linear trend. This suggests that either the GRACE data observe a different linear trend in the subpolar gyre than the JPL_ECCO model, or that estimated principal components for higher modes may have large trends of the opposite sign to compensate. The variance of EOF mode 1 for JPL_ECCO is $1.2 \mathrm{~cm}^{2}$ compared to $2.3 \mathrm{~cm}^{2}$ for an EOF reconstruction from only the first mode for GRACE (Table 1), which is due mainly to this apparent difference in trends.

[23] The principal components estimated from the GRACE grids for modes 2 through 4 are very close to those in the JPL_ECCO model (Figure 3) and do not show any significant trends and have similar variances. Additionally, when we compare the average of the EOFR filtered grids with the average from the original GRACE grids in a box defined by $30-50^{\circ} \mathrm{N}, 170-190^{\circ} \mathrm{E}$ (where the leading two JPL ECCO EOF modes have the largest amplitude) we note that the variations are nearly identical, with differences of only $0.4 \mathrm{~cm}$ RMS (compared to a total variation of $2.7 \mathrm{~cm}$ RMS), a correlation of 0.97 , and similar seasonal variations and trends. This suggests that the first four modes do adequately model the large-scale OBP variability in the region of largest $\mathrm{OBP}$ variability and that the trend is in the
GRACE observations and not an artifact of the EOFR filtering.

\section{Analysis and Discussion}

[24] After filtering the 300-km smoothed GRACE grids with the EOFR technique described in section 3, one finds the RMS of the GRACE OBP is now comparable to that of JPL_ECCO (Figure 4). Although the patterns and general size of the variability are similar, the magnitude of the GRACE OBP variability is still about $20 \%$ higher than that of JPL_ECCO, especially poleward of $30^{\circ}$ and west of $200^{\circ}$.

[25] The amplitudes (Figure 5) and phases (Figure 6) of the annual and semiannual periods are very similar in the GRACE and JPL ECCO OBP, although the GRACE amplitudes are slightly higher north of $30^{\circ}$. The annual variation in the tropics is due mainly to the combined effect of the global ocean mass and atmospheric pressure component of OBP, as the model without these terms has no annual variation here (not shown). Both the annual and semiannual signals are highly correlated over long wavelengths (as indicated by the consistent phase). The amplitudes are highest north of $30^{\circ}$ and west of $200^{\circ} \mathrm{E}$, so we compute the average OBP over a box defined by $30-50^{\circ} \mathrm{N}$ and $170-200^{\circ} \mathrm{E}$ (Figure 7). The annual and semiannual amplitudes and phases all agree within the formal errors (Table 2), and month-to-month variations are also highly correlated (Figure 7).

[26] Although a mean OBP signal was added to the JPL_ECCO maps, this does not explain all of the high correlation and for the seasonal periods (Figure 7). The amplitude of the seasonal variation is only $0.8 \mathrm{~cm}$, and the trend is less than $0.1 \mathrm{~cm}^{\text {year }}{ }^{-1}$ [e.g., Willis et al., 2008]. This explains less than $45 \%$ of the observed variation. Both JPL ECCO and GRACE show variations in local OBP that are several times larger than the global mean OBP.

[27] The largest difference between GRACE and JPL_ECCO OBP in this region is during 2003, when GRA ACE shows a significantly lower OBP anomaly. JPL_ECCO OBP is not significantly different from the 

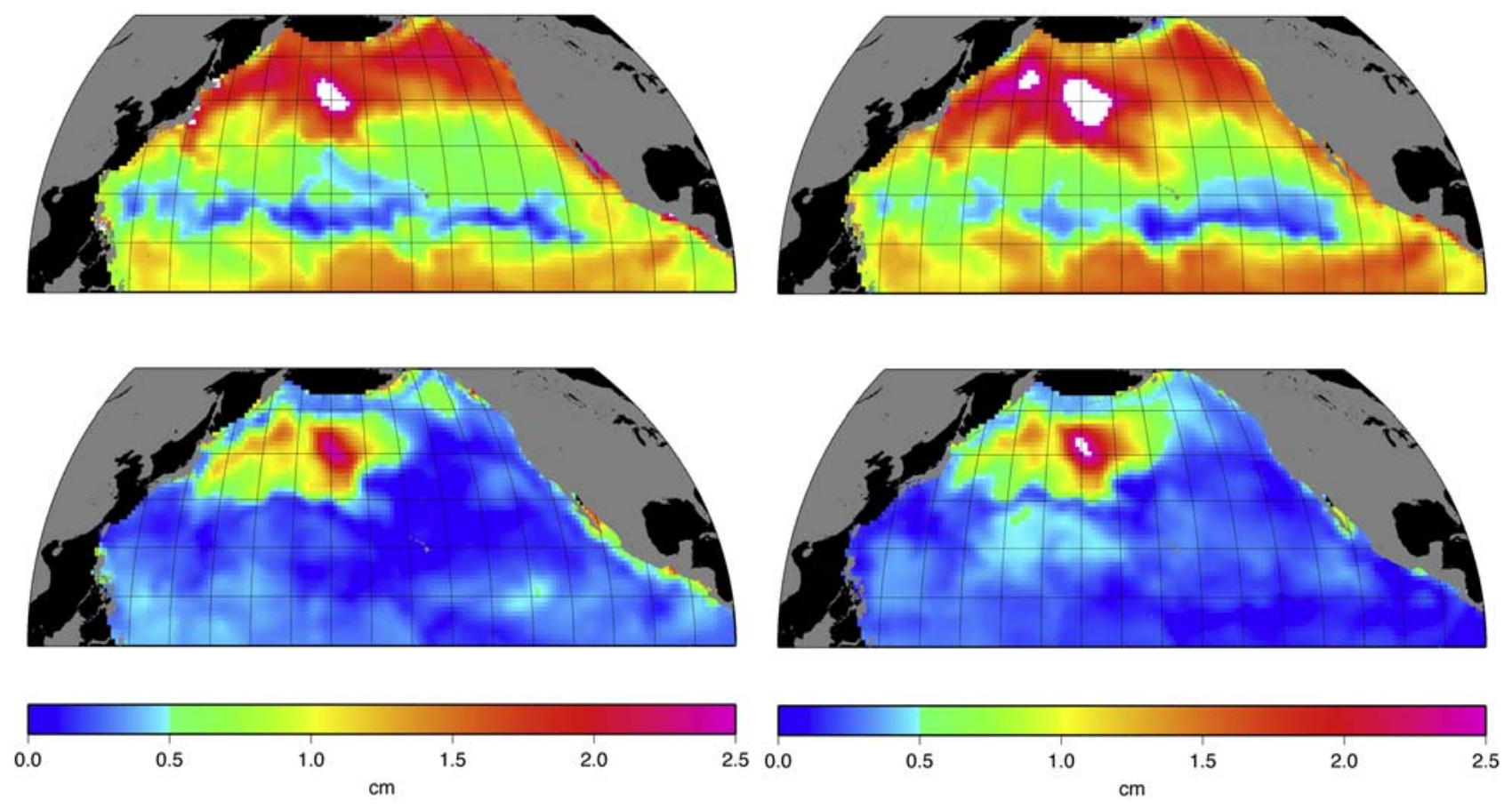

Figure 5. Amplitude of the annual (top) and semiannual (bottom) periods for JPL_ECCO (left) and GRACE after EOFR filtering (right).

mean seasonal variation during this period, while GRACE shows a rise from an OBP low. Song and Zlotniki [2008] also observed this low OBP in GRACE data, and were able to reproduce it in a non-Boussinesq ocean model forced by wind stress. They speculated it was related to ENSO events and demonstrated similar events in the model for earlier periods. Song and Zlotniki [2008] only used GRACE data through the end of 2005. In our longer time series, it also appears that during 2006 and early 2007 the GRACE OBP anomaly is slightly higher than that from JPL_ECCO, which is more evident when the mean seasonal variation is removed (Figure 8). This appears as a large linear trend over the entire region in the GRACE data, with only a minimal trend in the JPL_ECCO data (Figure 9). Over the
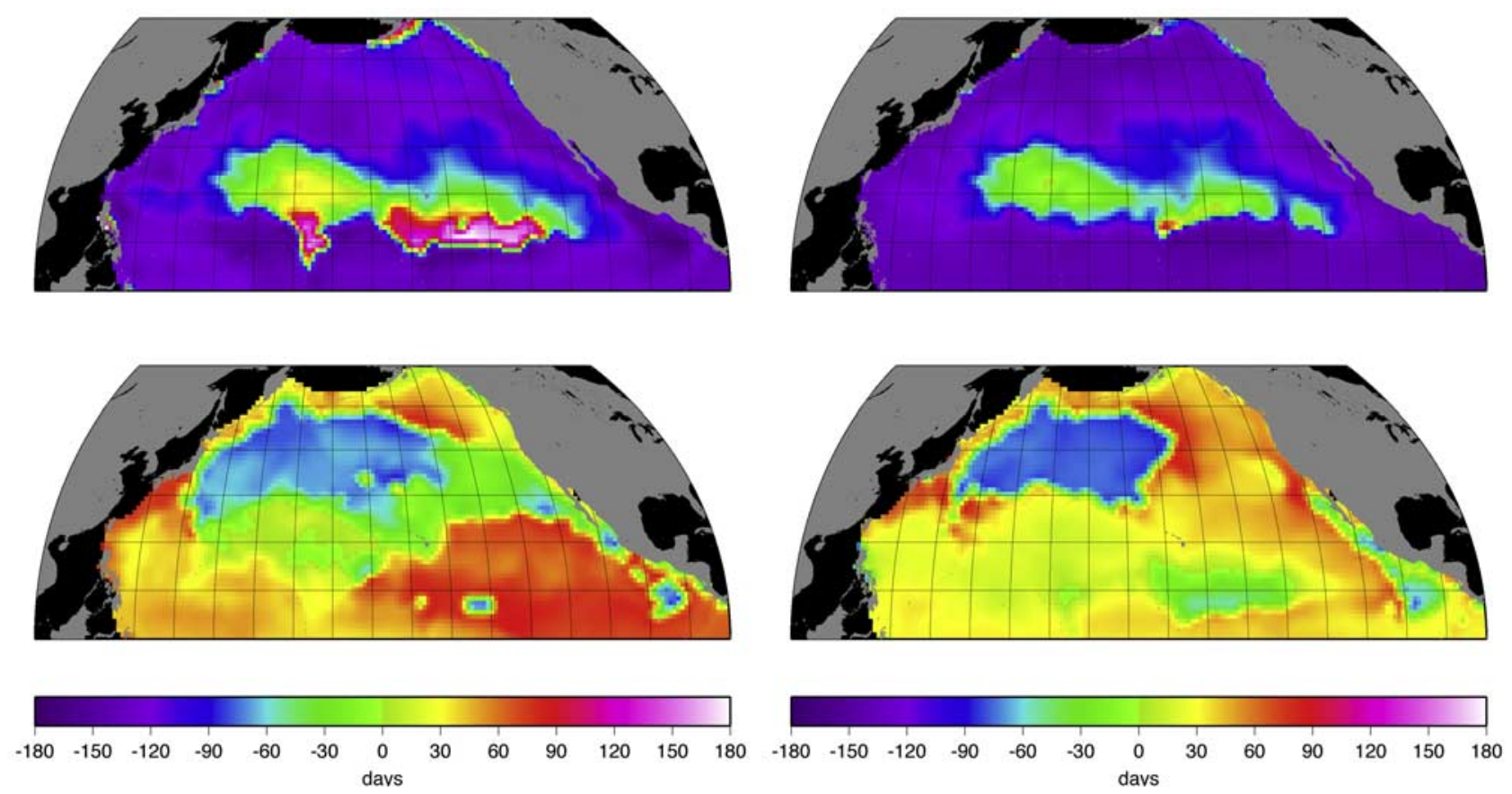

Figure 6. Phase of the annual (top) and semiannual (bottom) periods for JPL_ECCO (left) and GRACE after EOFR filtering (right). Phase is in days past 1 January and is calculated from $A \cos (\omega t$ phase). 


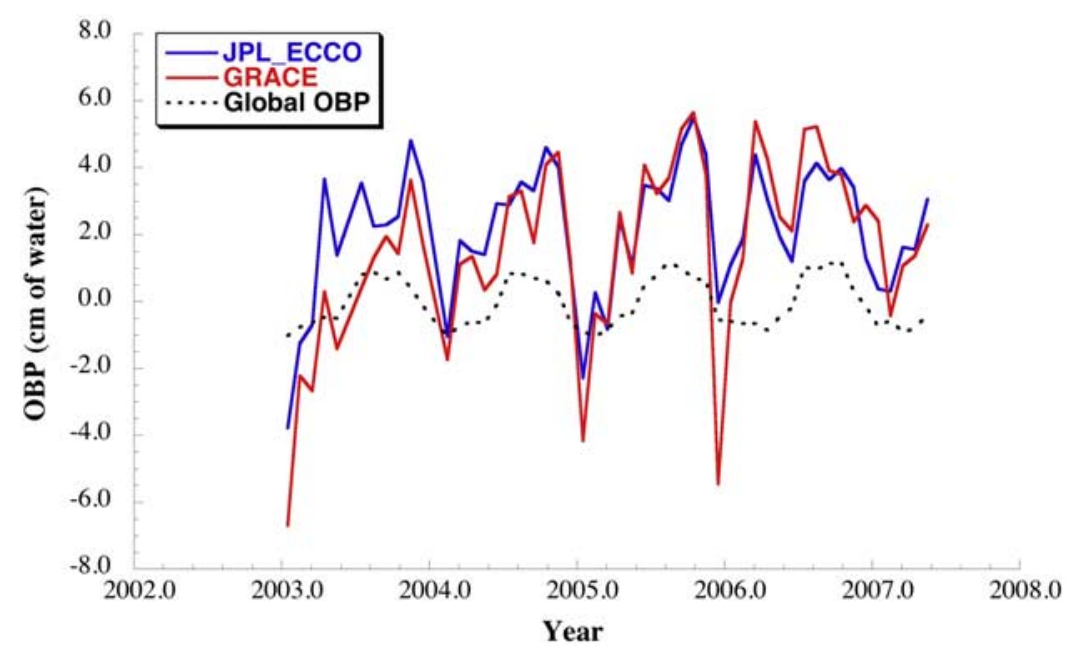

Figure 7. Average OBP from January 2003 until May 2007 in a box defined by $30-50^{\circ} \mathrm{N}$ and $170-$ $200^{\circ} \mathrm{E}$ for JPL_ECCO (blue), EOFR filtered GRACE data (red), and the global mean (black dots).

entire region, GRACE observes a mean trend of nearly $0.9 \mathrm{~cm}$ year $^{-1}$, which is three times larger than that predicted by JPL_ECCO. The linear trend is computed from fitting a bias and slope to the data from January 2003 until May 2007 using least squares estimation. The mean OBP is not the source of the large, interannual variations in this region (Figure 8), nor does it contribute more than about $0.1 \mathrm{~cm}$ year $^{-1}$ to the trend.

[28] Since the JPL_ECCO model does not show this signal, we have also examined the OBP inferred from the altimetry corrected for steric signals using data from Argo floats in the area in order to rule out an error in the GRACE observations. A $20^{\circ}$ longitude by $5^{\circ}$ latitude box was located in the region of study containing an adequate amount of Argo data that is close to the center of the subpolar gyre as well as the maximum in the trend and in GRACE OBP variability. When the GRACE data are averaged over this box $\left(40-45^{\circ} \mathrm{N}, 160-180^{\circ} \mathrm{E}\right)$ and compared to the Altimeter-Argo OBP we find very good agreement (Figure 10). The RMS of the difference of the 5 -month smoothed interannual variations is $0.5 \mathrm{~cm}$, the correlation is 0.94 , and both time series show a similar rise from much lower than normal OBP during 2003 to slightly higher than normal OBP in 2006. Although this box is smaller than the box used for Figure 8, the two GRACE time series are nearly identical (RMS of difference $=0.3 \mathrm{~mm}$, correlation $=0.98$ ), which indicates that the smaller averaging box is representative of the larger region.

[29] Since this interannual fluctuation in OBP is observed in two independent sources of data, we conclude it is a real signal that is not reproduced in the JPL_ECCO model. In order to obtain a clue as to why the signal may not be reproduced in JPL_ECCO, we have compared the total sea surface height $(\mathrm{SSH})$ anomalies from the model with the observations from Jason-1 in the same region, as well as the steric component of JPL_ECCO with the steric anomalies from Argo (Figure 11). Although the steric variations in the model and data are very similar, the total SSH variations are not, even though JPL_ECCO assimilated Jason-1 data. Jason-1 SSH anomalies are from 1 to $3 \mathrm{~cm}$ lower than JPL_ECCO SSH throughout 2003, exactly at the time when
GRACE observes a lower than normal OBP. During 2006, Argo steric anomalies are 1 to $2 \mathrm{~cm}$ lower than JPL ECCO steric anomalies, while in late 2006 through early 2007, Jason-1 SSH anomalies are 1 to $2 \mathrm{~cm}$ higher than JPL_ECCO SSH anomalies. These observations are entirely consistent with the higher than normal OBP observed by GRACE in 2006, but not in the model. Although this run of the JPL_ECCO model assimilated Jason-1 altimetry, these observations suggest that the assimilation rejected part of the signal in the Jason-1 observations that was related to OBP variability.

[30] Song and Zlotnicki [2008] suggested in their study with the non-Boussinesq ocean model that the OBP in this region may be correlated with ENSO variability, but shifted in phase. For example, they found that OBP in this region was lower than normal shortly after peak El Niño warming in their model and was higher than normal shortly before peak El Niño warming. According to the indices and analysis distributed at the NOAA Climate Diagnostic Center, there were moderate El Niño events that peaked in late 2002 and late 2007 (Figure 12). Our GRACE time series is far too short to do any correlation analysis between GRACE OBP and ENSO as Song and Zlotnicki [2008] did with the ocean model run, but the GRACE observations are largely consistent with their findings; that is, OBP in the subpolar gyre was lower than normal shortly after the 2002 El Niño and higher than normal several months before the $2007 \mathrm{El}$ Niño peaked. This could also be an interannual fluctuation that is unrelated to ENSO. However, if it is ENSO-related,

Table 2. Seasonal Cycle Amplitudes, Phase, and Slope of Trend for Average OBP in the Area Bounded by $30-50^{\circ} \mathrm{N}$ and $170-$ $200^{\circ} \mathrm{E}^{\mathrm{a}}$

\begin{tabular}{|c|c|c|}
\hline & JPL_ECCO & GRACE \\
\hline Annual Amplitude (cm) & $1.75 \pm 0.26$ & $2.09 \pm 0.37$ \\
\hline Annual Phase $\left({ }^{\circ}\right)$ & $235.2 \pm 8.6$ & $229.2 \pm 10.3$ \\
\hline Semiannual Amplitude $(\mathrm{cm})$ & $1.02 \pm 0.26$ & $1.08 \pm 0.38$ \\
\hline Semiannual Phase $\left({ }^{\circ}\right)$ & $220.3 \pm 14.7$ & $200.7 \pm 19.8$ \\
\hline Trend $\left(\mathrm{cm}\right.$ year $\left.^{-1}\right)$ & $0.31 \pm 0.15$ & $0.89 \pm 0.21$ \\
\hline
\end{tabular}

${ }^{\mathrm{a}}$ The fit was computed from January 2003 until May 2007. 


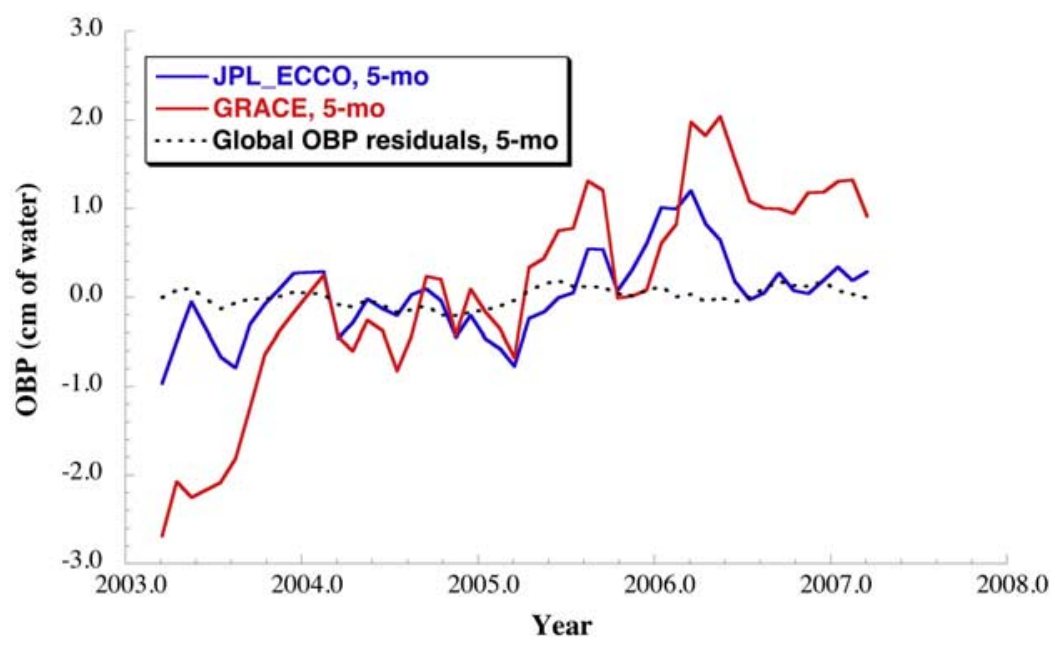

Figure 8. Figure 7 with the mean seasonal variation removed and after applying a 5-month running mean boxcar for JPL_ECCO (blue), EOFR filtered GRACE data (red), and the global mean (black dots). Note that we have also included EOFR filtered GRACE data GRACE observations from August to December 2002 and June to December 2007.

as Song and Zlotnicki [2008] theorize, then we would expect another interannual drop in the OBP in this region in 2008 since the $2007 \mathrm{El} \mathrm{Niño} \mathrm{has} \mathrm{peaked} \mathrm{and} \mathrm{transitioned}$ to a La Niña. As of this writing, however, we do not have GRACE measurements past January 2008 and there has been no observed transition to lower than normal OBP in the area (Figure 8), so confirmation of the Song and
Zlotnicki [2008] hypothesis this will have to be tested in the future.

\section{Conclusions}

[31] Although GRACE measurements have been shown to have high OBP variability in regions predicted by models, the RMS of the variations are significantly higher

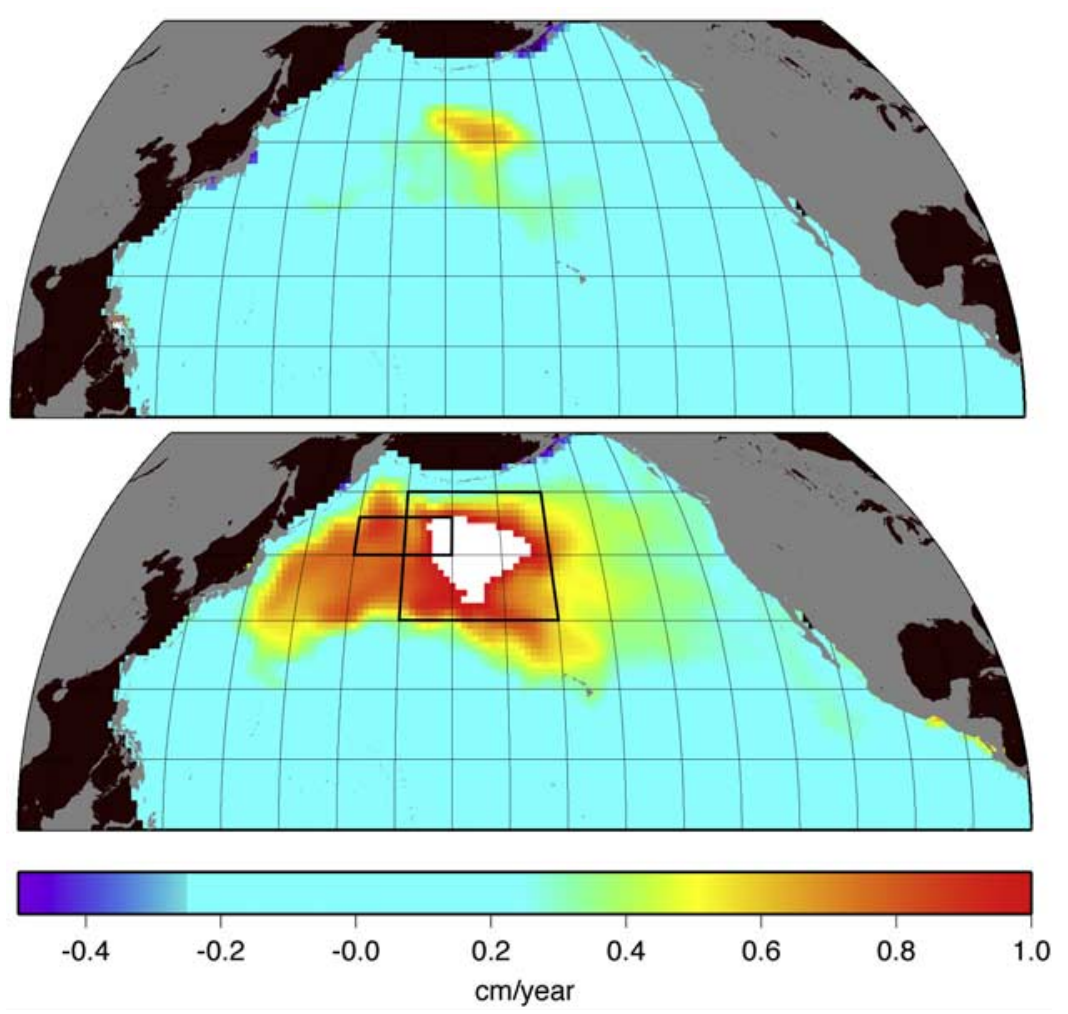

Figure 9. Trend in ocean bottom pressure from January 2003 to May 2007 for JPL_ECCO (top) and GRACE after EOFR filtering (bottom). The black boxes indicate the two areas where data are averaged for Figures 7, 8, and 10. 


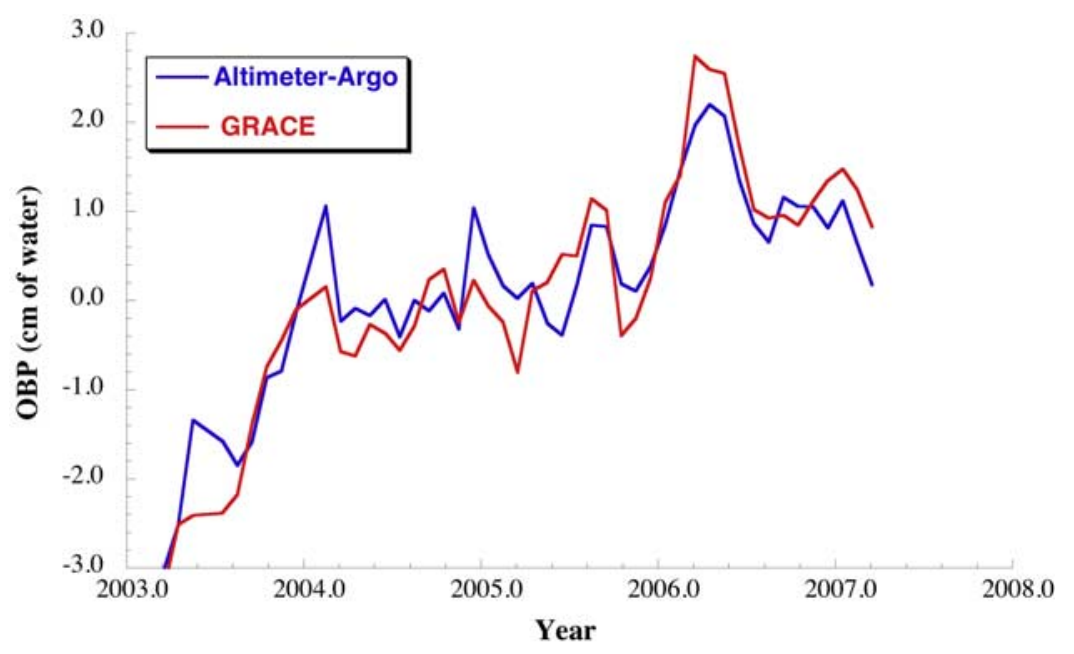

Figure 10. Average $\mathrm{OBP}$ in the area defined by $40^{\circ}-45^{\circ} \mathrm{N}, 160^{\circ}-180^{\circ} \mathrm{E}$ after removing mean seasonal variation and smoothing with a 5-month running mean for Altimeter-Argo (blue) and EOFR filtered GRACE data (red).
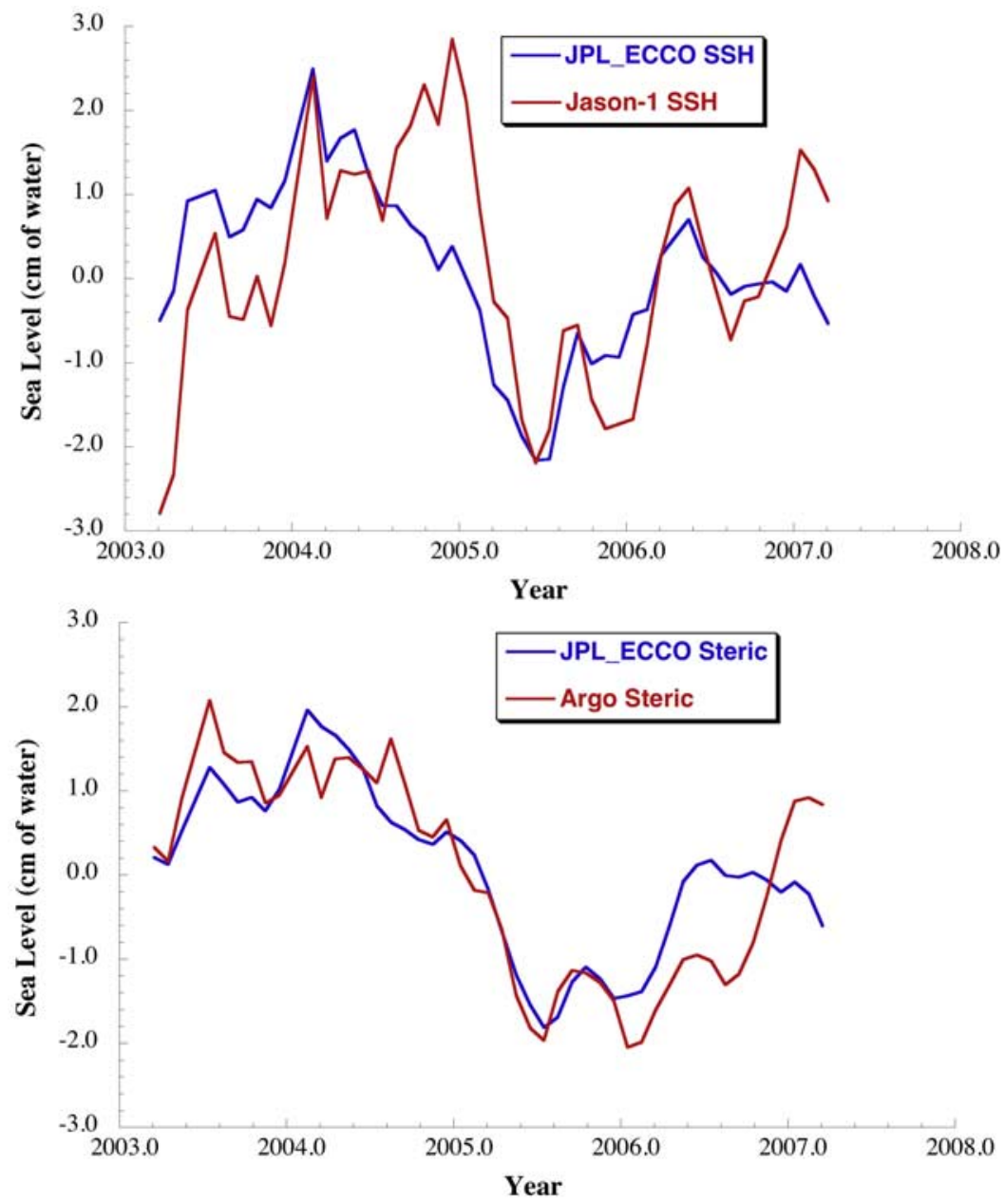

Figure 11. Average sea level anomalies in the area defined by $40-45^{\circ} \mathrm{N}, 160^{\circ}-180^{\circ} \mathrm{E}$ after removing mean seasonal variation and smoothing with a 5-month running mean for total $\mathrm{SSH}$ (top) and steric component (bottom). In both cases, the model output is blue and the direct observation is red. 


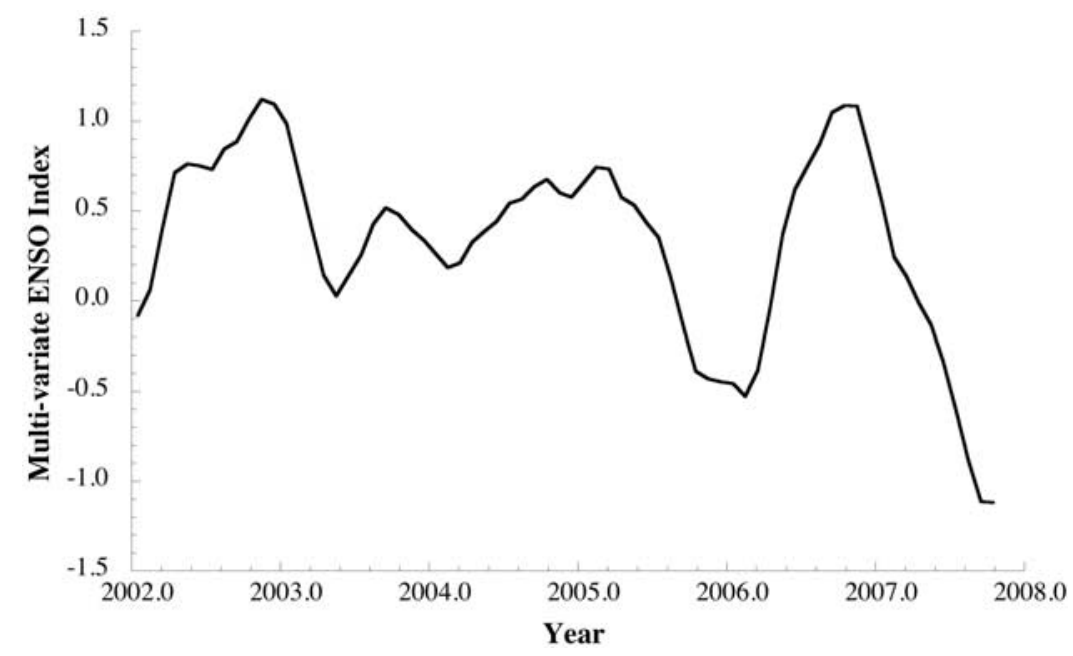

Figure 12. Multivariate ENSO index [Wolter and Timlin, 1998]. Positive values indicate ENSO, while negative numbers represent La Niña. Values are normalized and represent relative strengths of events. Data are from the NOAA Climate Diagnostic Center (http://www.cdc.noaa.gov/people/klaus.wolter/MEI/).

than predicted by an ocean model. Much of this is due to noise in the measurements, which we have demonstrated can be reduced significantly using an EOF Reconstruction filtering based on projecting GRACE data onto the first four EOF modes from an ocean model, then reconstructing the grids based on the EOFs and principal components.

[32] After reducing the noise, the GRACE measurements agree better with the OBP predicted from the JPL_ECCO model in the north Pacific. However, there are still significant differences. Although annual and semiannual variations are similar, GRACE observes large, correlated interannual fluctuations poleward of $30^{\circ}$, where OBP increases from a low of nearly $3 \mathrm{~cm}$ below normal in early 2003 to normal throughout 2004 and 2005, then an increase of roughly half that magnitude in 2006 . These fluctuations have also been observed in OBP inferred from satellite altimetry corrected for steric variations computed from Argo float data.

[33] Thus we conclude that there is a significant lowfrequency fluctuation in the North Pacific between January 2003 and December 2007 and that this signal is underestimated by the JPL_ECCO ocean model, even though the model has assimilated both satellite altimetry and in situ temperature and salinity profiles. We have demonstrated that the model SSH and steric variability does not match the assimilated observations in 2003 and 2006, which indicates the assimilation rejected some portion of the observed signal. However, as we have demonstrated via comparison with the independent GRACE observations, the rejected signal was related to real OBP variations. Further investigation will be necessary to fully quantify the model/observation differences as it relates to the assimilation, and a comparison of results between Boussinesq and non-Boussinesq models should be pursued as the non-Boussinesq model of Song and Zlotnicki [2008] appears to contain interannual variability that is significantly different than the JPL_ECCO model and is closer to GRACE observations. This has important implications to the analysis of interannual fluctuations in ocean models, since most use the
Boussinesq approximation. It is also too early to tell if these data support the theory of Song and Zlotnicki [2008] that the subpolar gyre has interannual fluctuations in OBP shortly before and after peak El Niño warming, although the short record appears to be consistent with their hypothesis. We look forward to longer time series of GRACE, altimetry and Argo data to help us answer this question.

[34] Acknowledgments. We would like to thank I. Fukumori for providing the output of the JPL_ECCO runs and for useful discussions on this paper. The data are a contribution of the Consortium for Estimating the Circulation and Climate of the Ocean (ECCO) funded by the National Oceanographic Partnership Program. GRACE data were processed under NASA Earth Science REASoN GRACE Project and are available at http:// grace.jpl.nasa.gov. The altimeter products were produced by Ssalto/Duacs and distributed by AVISO with support from CNES and are available at http://www.aviso.oceanobs.com/en/data. The float data were collected and made freely available by the International Argo Project (a pilot program of the Global Ocean Observing System) and contributing national programs and are available at http://www.argo.net. Finally, we would like to thank the two anonymous reviewers of this paper who made several important suggestions for improving this paper. This research was carried out under a grant from the NASA GRACE Science Team.

\section{References}

Antonov, J. I., S. Levitus, and T. P. Boyer (2005), Thermosteric sea level rise, 1955-2003, Geophys. Res. Lett., 32, L12602, doi:10.1029/ 2005 GL023112.

Bettadpur, S. (2007), Level-2 Gravity Field Product User Handbook, GRACE 327-734, CSR Publ. GR-03-01, Rev 2.3, University of Texas at Austin, $19 \mathrm{pp}$.

Bingham, R. J., and C. W. Hughes (2006), Observing seasonal bottom pressure variability in the North Pacific with GRACE, Geophys. Res. Lett., 33, L08607, doi:10.1029/2005GL025489.

Cane, M. A., A. Kaplan, R. N. Miller, B. Tang, E. C. Hackert, and A. J. Busalacchi (1996), Mapping tropical Pacific sea level: Data assimilation via a reduced state space Kalman filter, J. Geophys. Res., 101, 22,59922,618 .

Chambers, D. P. (2006a), Evaluation of new GRACE time-variable gravity data over the ocean, Geophys. Res. Lett., 33, L17603, doi:10.1029/ 2006GL027296.

Chambers, D. P. (2006b), Observing seasonal steric sea level variations with GRACE and satellite altimetry, J. Geophys. Res., 111, C03010, doi:10.1029/2005JC002914.

Chambers, D. P. (2007), Converting Release-04 Gravity Coefficients Into Maps of Equivalent Water Thickness, 9 pp. (Available at ftp://podaac.jpl. nasa.gov/pub/tellus/monthly_mass_grids/chambers-destripe-RL04200711/doc/ GRACE-dpc20071̄1_RLË4.pdf) 
Chambers, D. P., J. L. Chen, R. S. Nerem, and B. D. Tapley (2000), Interannual sea level change and the earth's water mass budget, Geophys. Res. Lett., 27, 3073-3076.

Chambers, D. P., C. A. Mehlhaff, T. J. Urban, D. Fujii, and R. S. Nerem (2002), Low frequency variations in global mean sea level: 1950-2000, J. Geophys. Res., 107(C4), 3026, doi:10.1029/2001JC001089.

Chambers, D. P., J. Wahr, and R. S. Nerem (2004), Preliminary observations of global ocean mass variations with GRACE, Geophys. Res. Lett., 31, L13310, doi:10.1029/2004GL020461.

Chen, J. L., C. R. Wilson, D. P. Chambers, R. S. Nerem, and B. D. Tapley (1998), Seasonal global water mass balance and mean sea level variations, Geophys. Res. Lett., 25, 3555-3558.

Church, J. A., N. J. White, R. Coleman, K. Lambeck, and J. X. Mitrovica (2004), Estimates of the regional distribution of sea-level rise over the 1950 to 2000 period, J. Clim., 17, 2609-2625.

Ducet, N., P. Y. LeTraon, and G. Reverdin (2000), Global high-resolution mapping of ocean circulation from TOPEX/Poseidon and ERS-1 and -2, J. Geophys. Res., 105, 19,477-19,498.

Flechtner, F. (2007), AOD1B Product Description Document for Product Releases 01 to 04, GRACE 327-750, CSR publ. GR-GFZ-AOD-0001 Rev. 3.1, University of Texas at Austin, $43 \mathrm{pp}$.

Fukumori, I., R. Raghunath, L. Fu, and Y. Chao (1999), Assimilation of TOPEX/POSEIDON data into a global ocean circulation model: How good are the results?, J. Geophys. Res., 107, 25,647-25,665.

Gill, A. E., and P. P. Niiler (1973), The theory of seasonal variability in the ocean, Deep Sea Res., 20, 141-177.

Gouretski, V. V., and K. P. Koltermann (2004), WOCE global hydrographic climatology [CD-ROM], Ber. Bundesamt Seeschiffahrt Hydrogr. Rep., 35, 52 pp., Bundesamt Seeschiffahrt Hydrogr., Hamburg, Germany.

Guinehut, S., P.-Y. Le Traon, and G. Larnicol (2006), What can we learn from global altimetry/hydrography comparisons?, Geophys. Res. Lett., 33, L10604, doi:10.1029/2005GL025551.

Hughes, C. W., and M. J. Smithson (1996), Bottom pressure correlations in the south Atlantic, Geophys. Res. Lett., 23, 2243-2246.

Kanzow, T., F. Flechtner, A. Chave, R. Schmidt, P. Schwintzer, and U. Send (2005), Seasonal variation of ocean bottom pressure derived from Gravity Recovery and Climate Experiment (GRACE): Local validation and global patterns, J. Geophys. Res., 110, C09001, doi:10.1029/2004JC002772.

Kaplan, A., Y. Kushnir, M. A. Cane, and M. B. Blumenthal (1997), Reduced space optimal interpolation of historical data sets: 136 years of Atlantic sea surface temperature, J. Geophys. Res., 102, 27,835-27,860.

Kaplan, A., Y. Kushnir, and M. A. Cane (2000), Reduced space optimal interpolation of historical marine sea level presssure: 1854-1992, J. Clim., 13, 2987-3002.

Marshall, J., A. Adcroft, C. Hill, L. Perelman, and C. Heisey (1997), A finite-volume, incompressible Navier-Stokes model for studies of the ocean on parallel computers, J. Geophys. Res., 102, 5753-5766.

Preisendorfer, R. W. (1988), Principal Component Analysis in Meteorology and Oceanography, edited by C. Mobley, 418 pp., Elsevier, New York.

Ponte, R. (1999), A preliminary model study of the large-scale seasonal cycle in bottom pressure over the global ocean, J. Geophys. Res., 104, $1289-1300$.
Ponte, R. M., K. J. Quinn, C. Wunsch, and P. Heimbach (2007), A comparison of model and GRACE estimates of the large-scale seasonal cycle in ocean bottom pressure, Geophys. Res. Lett., 34, L09603, doi:10.1029/ 2007GL029599.

Shen, S. S. P., G. R. North, and K. Y. Kim (1994), Spectral approach to optimal estimation of the global average temperature, J. Clim., 7, 19992007.

Shriver, J. F., and J. J. O'Brien (1995), Low-frequency variability of the equatorial Pacific ocean using a new pseudostress dataset: 1930-1989, J. Clim., 8, 2762-2786.

Smith, T. M., R. W. Reynolds, R. E. Livezey, and D. C. Stokes (1996), Reconstruction of historical sea surface temperatures using empirical orthogonal functions, J. Clim., 9, 1403-1420.

Song, Y. T., and V. Zlotnicki (2008), Subpolar ocean-bottom-pressure oscillation and its links to the tropical ENSO, Int. J. Remote Sens., in press.

Swenson, S. C., and J. Wahr (2006), Post-processing removal of correlated errors in GRACE data, Geophys. Res. Lett., 33, L08402, doi:10.1029/ 2005GL025285.

Tapley, B. D., S. Bettadpur, M. Watkins, and C. Reigber (2004), The gravity recovery and climate experiment: Mission overview and early results, Geophys. Res. Lett., 33, L09607, doi:10.1029/2004GL019920.

Vivier, F., K. A. Kelly, and M. Harismendy (2005), Causes of large-scale sea level variations in the Southern Ocean: Analyses of sea level and a barotropic model, J. Geophys. Res., 110, C09014, doi:10.1029/ 2004JC002773.

Wahr, J., M. Molenaar, and F. Bryan (1998), Time-variability of the Earth's gravity field: Hydrological and oceanic effects and their possible detection using GRACE, J. Geophys. Res., 103, 30,205-30,229.

Wahr, J., S. Swenson, V. Zlotnicki, and I. Velicogna (2004), Time-variable gravity from GRACE: First results, Geophys. Res. Lett., 31, L11501, doi:10.1029/2004GL019779.

Willis, J. K., D. P. Chambers, and R. S. Nerem (2008), Assessing the globally averaged sea level budget on seasonal to interannual time scales, J. Geophys. Res., 113, C06015, doi:10.1029/2007JC004517.

Wolter, K., and M. S. Timlin (1998), Measuring the strength of ENSO events - How does 1997/98 rank?, Weather, 53, 315-324.

Woodworth, P. L., J. M. Vassie, C. W. Hughes, and M. P. Meredith (1996), A test of the ability of TOPEX/POSEIDON to monitor flows through the drake passage, J. Geophys. Res., 101, 11,935-11,947.

Zlotnicki, V., J. Wahr, I. Fukumori, and Y. T. Song (2007), Antarctic circumpolar current transport variability during 2003-05 from GRACE, J. Phys. Oceanol., 37, 230-244.

D. P. Chambers, Center for Space Research, University of Texas at Austin, 3925 W. Braker Lane, Suite 200, Austin, TX 78759-5316, USA. (chambers@csr.utexas.edu)

J. K. Willis, NASA Jet Propulsion Laboratory, California Institute of Technology, M/S 300-323, 4800 Oak Grove Drive, Pasadena, CA 91109, USA. 